\title{
Role of pleural fluid adenosine deaminase activity and lymphocytosis in the etiological diagnosis
}

\author{
Pande $\mathrm{K}^{1}$, Shrestha $\mathrm{S}^{2}$, Shrestha $\mathrm{A}^{3}$, Prasad KBR ${ }^{1}, \mathrm{~S}$ K Rauniyar ${ }^{1}$, Pudasaini $\mathrm{S}^{1}$, \\ Pathak R ${ }^{1}$
}

${ }^{I}$ Department of Pathology, Nepal Medical College and Teaching Hospital, Kathmandu,Nepal.

${ }^{2}$ Department of Pathology, Norvic International Hospital, Kathmandu,Nepal

${ }^{3}$ Department of Pediatrics, Kathmandu Medical College Teaching Hospital, Kathmandu, Nepal

\section{Keywords:}

Adenosine Deaminase;

Lymphocytosis;

Pleural effusion;

Tuberculosis

\begin{abstract}
Background: Pleural effusion is a common medical condition with many possible underlying etiologies. However, Tuberculosis is the most common cause of pleural effusion especially in countries like Nepal. Pleural fluid lymphocytosis is seen in tuberculosis, malignancy and few auto-immune diseases. Adenosine Deaminase activity (ADA) level in tubercular pleural effusion is markedly increased compared to non-tubercular effusions. ADA estimation being a simple colorimetric method is suitable for the rapid diagnosis of tubercular effusion. This study aims to correlate the diagnostic efficacy of ADA with the value of differential count (lymphocytosis) in establishing different etiology of pleural effusion.
\end{abstract}

Materials and Methods: This is a cross sectional study of 50 cases with pleural effusion carried out in the department of Pathology, Green city hospital for the duration of Twenty one month's dating from October 2014 to July 2016 AD.

Results: Of all, tubercular pleural effusion accounted for $26 \%$. ADA level was raised ( $\geq 40 \mathrm{U} / \mathrm{L})$ in $92 \%$ of Tubercular pleural effusion. The sensitivity and specificity of ADA alone to diagnose tubercular pleural effusion was $92 \%$ each and when lymphocytosis alone was considered sensitivity was $85 \%$ with specificity of $32 \%$ whereas the combined effect of both ADA with lymphocytosis was $100 \%$ (sensitivity) and $87 \%$ (specificity), $83 \%$ (positive predictive value) and 100\% (negative predictive value) respectively with statistically significant $\mathrm{p}$ value $(<0.05)$.

Conclusion: We can conclude that the combination of pleural fluid differential count (lymphocytosis $>50 \%$ ) and ADA level $>40 \mathrm{U} / \mathrm{L}$ provides with much more positive result than each component alone in differentiating tubercular effusion from other etiologies.

\section{INTRODUCTION}

Pleural effusion is the end result of many pulmonary as well as other systemic diseases. It requires diagnostic and/or

\section{Correspondence:}

Dr Kricha Pande, MBBS, MD

Department of Pathology, Nepal Medical College and Teaching Hospital and Green city Hospital, Kathmandu,Nepal

Email:krichapande@gmail.com therapeutic tapping in most cases to make a final etiological diagnosis. In country like Nepal, where tuberculosis (TB) is very rampant and with the evolution of multidrug resistance, there has been a need of simple, rapid, cost effective and reliable diagnostic test to establish the etiology of pleural effusion. 
The analysis of pleural fluid includes total and differential count, biochemical examination as well as cytology and microbiology depending upon the type of case. Neutrophilic predominant exudative effusions are due to acute processes whereas lymphocytic effusions have a much longer list of differential diagnoses. However, in areas with high incidence of tuberculosis, tuberculosis and malignancy are the most likely cause of lymphocytic pleural effusion. ${ }^{1}$ Pleural fluid lymphocytosis can be seen in malignancy, collagen vascular disease, sarcoidosis and up to third of all transudates. Para pneumonic and emphysematous effusions are characterized by neutrophils-predominant, exudative effusions. ${ }^{2}$

Adenosine Deaminase activity (ADA) analysis in effusion as well as in serum are in practice as this is the cheapest test with high diagnostic value. Adenosine Deaminase is an enzyme in the purine salvage pathway required for converting adenosine to inosine. Its level is ten times higher in lymphocytes than in erythrocytes and particularly in $\mathrm{T}$ lymphocytes. $^{3}$ ADA level in tubercular pleural effusion is markedly increased compared to non-tubercular effusions. ADA estimation being a simple colorimetric method is imminently suitable for the rapid diagnosis of tubercular effusion. ${ }^{4}$ ADA levels in the pleural fluid are estimated by the spectrophotometric method described by Guisti. ${ }^{3}$

There has been a need to study the diagnostic efficacy of ADA and the value of differential count (lymphocytosis) in establishing the etiological diagnosis (tubercular versus non tubercular) pleural effusion, in countries like Nepal where the cost effectiveness of each test counts.

\section{MATERIALS AND METHODS}

Study Design and samples: A cross sectional study was conducted in the department of pathology, Green city hospital for the duration of twenty-one months from October 2014 to July 2016. Clearance from the institutional review committee was obtained. The study comprised of 50 selected patients with pleural effusion (in-patients as well as OPD based). A thorough history, examination and confirmation of effusion by chest $\mathrm{x}$-ray or ultrasound was done in all patients. Pleural tapping was done by clinicians and radiologists under full aseptic precaution. Both ultrasound guided as well as blind tapping were included.

Pleural fluid analysis: The pleural fluid sent to the laboratory was analyzed for gross findings, biochemical findings, total and differential count of pleural fluid, ADA level in pleural effusion. The volume, color and transparency were noted in physical examination. Total count was obtained manually via neubaur chamber whereas Wright's stained slides were prepared for differential count. Lymphocytic effusions were defined as effusions with a lymphocyte count $>50 \%$ of the total nucleated cells ${ }^{5}$.

The pleural fluid was analyzed for protein, albumin, sugar, lactate dehydrogenase (LDH) and ADA levels. Centrifuge preparation and cytology (Papaniculaou and Giemsa stain) for malignant cells were also done as and when required.

Special stain (AFB-TB) and gram stain: Ziehl Neelsen stain (AFB-TB) and Gram stain was done for the suspected patients of tuberculosis, pneumonia and lung abscess.

Presence of first or more than one of the following criteria was adopted to label a case as tuberculosis:

(1) Bacteriological confirmation of Mycobacterium tuberculosis (identification of the bacillus in the pleural fluid or biopsy specimen by stain or by culture);

(2) Histopathology finding of caseating granulomas;

(3) Radiological findings consistent with TB;

(4) Clinical presentation consistent with TB with positive tuberculin test ( $>20 \mathrm{~mm}$ indurations) with exclusion of other clinical considerations;

(5) Definite clinical and radiological improvement in 2 months of administration of exclusive anti-tubercular treatment.

Table 1: Causes, gender and age distributions in pleural effusion

\begin{tabular}{|c|c|c|c|c|}
\hline Diseases & n (Number) & $\%($ Percentage) & Males/Females & Age, years (mean) \\
\hline Tuberculosis & 13 & 26 & $10 / 3$ & 34.6 \\
\hline Infectious-Pneumonia & 05 & 10 & $4 / 1$ & 54.8 \\
\hline COPD & 09 & 18 & $6 / 3$ & 71.7 \\
\hline Neoplastic & 03 & 6 & $2 / 1$ & 65.3 \\
\hline Autoimmune & 01 & 2 & $0 / 1$ & \\
\hline Idiopathic & 07 & 14 & $3 / 4$ & 57.0 \\
\hline Trauma (RTA) & 04 & 08 & $4 / 0$ & 41.2 \\
\hline Miscellaneous & 08 & 16 & $5 / 3$ & 47.0 \\
\hline Total & 50 & 100 & $34 / 16$ & 53.0 \\
\hline
\end{tabular}


Table 2: ADA activity in tuberculous and non tuberculous pleural effusion

\begin{tabular}{llcc}
\hline $\begin{array}{l}\text { ADA in Pleural fluid( } \\
\text { U/L) }\end{array}$ & $\begin{array}{l}\text { Tuberculosis } \\
\text { pleural effu- } \\
\text { sion }\end{array}$ & $\begin{array}{l}\text { Non Tubercu- } \\
\text { lous pleural } \\
\text { effusion }\end{array}$ & Total \\
\hline More than 40U/L & $\mathbf{1 2}$ & 3 & 15 \\
\hline Less than 40U/L & $\mathbf{1}$ & 34 & 35 \\
\hline Total & $\mathbf{1 3}$ & $\mathbf{3 7}$ & $\mathbf{5 0}$ \\
\hline
\end{tabular}

Table 3: Differential lymphocyte count in tuberculous and non tuberculous pleural effusion

\begin{tabular}{llcc}
\hline $\begin{array}{l}\text { Lymphocyte count in } \\
\text { pleural fluid }\end{array}$ & $\begin{array}{l}\text { Tuberculous } \\
\text { pleural effu- } \\
\text { sion }\end{array}$ & $\begin{array}{l}\text { Non Tubercu- } \\
\text { lous pleural } \\
\text { effusion }\end{array}$ & Total \\
\hline$>50 \%$ & $\mathbf{1 1}$ & 25 & 36 \\
$<50 \%$ & $\mathbf{2}$ & 12 & 14 \\
\hline Total & $\mathbf{1 3}$ & $\mathbf{3 7}$ & $\mathbf{5 0}$ \\
\hline
\end{tabular}

Table 4: Comparison between ADA activity and Lymphocytosis in tuberculous and non tuberculous pleural effusion

\begin{tabular}{llccc}
\hline ADA and Lymphocytosis (pleural fluid) & Tuberculous pleural effusion & $\begin{array}{l}\text { Non Tuberculous pleural ef- } \\
\text { fusion }\end{array}$ & Total & P value \\
\hline$>40 \mathrm{u} / \mathrm{l}$ and $>50 \%$ Lymphocytosis & 10 & 2 & 12 & $<0.0006$ \\
$<40 \mathrm{u} / \mathrm{l}$ and $<50 \%$ Lymphocytosis & 00 & 11 & 11 & $\mathbf{2 3}$
\end{tabular}

Effusion was called malignant when pleural fluid cytology or pleural biopsy showed evidence of malignancy or if the patient had proved metastatic malignancy with no other detectable cause of effusion. ${ }^{2,6}$

Determination of ADA level: Adenosine Deaminase was estimated by Giusti and Galanti colorimetric method (spectrophotometric method). ${ }^{3}$ The ADA value $30-40$ Unit/liter (U/L) was kept as suspected whereas 40-60 U/L was taken as strong suspect and more than $60 \mathrm{U} / \mathrm{L}$ was considered as positive for tuberculosis. All cases within the range 30-40 U/L were considered negative if clinical features did not correlate. Since the most widely accepted cut-off level of ADA for the diagnosis of tubercular pleural effusion is $40 \mathrm{U} / \mathrm{L}$, in this present study we took $\mathrm{ADA} \geq 40$ $\mathrm{U} / \mathrm{L}$ as in agreement with other studies. ${ }^{6}$ So, strong suspects were also considered as positive if other clinical features were suggestive of Tuberculosis.

\section{Statistical analysis}

The results were subjected to manual analysis. Mean, percentage, Chi squared tests (with Fischer's exact correction), sensitivity, specificity, positive and negative predictive value were calculated.

\section{RESULTS}

Both male and female patients in the age group of 16 to 87 years were included. Thirteen $(26 \%)$ out of fifty (50) patients had tuberculosis. The mean age of the patients with tuberculosis pleural effusion $(n=13)$ was 34.6years (Range: 18-65); there were 10 males. The mean age of patients with non tuberculosis pleural effusion $(n=37)$ was 56.2 years (Range 16-87); there were 24 males. Causes of non tubercular pleural effusions were Para pneumonic effusions, COPD, Trauma, miscellaneous, Idiopathic, Neoplastic and autoimmune causes.
Etiology, age and gender distribution are depicted in Table 1. Our study showed $92 \%$ of the tubercular pleural effusion had ADA level of more than or equal to $40 \mathrm{U} / \mathrm{L}$ and most of the non-tubercular origin of effusion had ADA lower than the cut off value which was expected, illustrated numerically on Table 2.

Table 3 shows that Lymphocytosis was more in tubercular pleural effusion (87\%) as well as in non-tubercular effusion (68\%). Table 4 and 5 shows the correlation between ADA activity and Lymphocytosis.

The sensitivity and specificity of ADA alone to diagnose tubercular pleural effusion was 92\% each and when lymphocyte alone was considered sensitivity was $85 \%$ with specificity of $32 \%$ whereas the combined effect of ADA in effusion with pleural fluid lymphocytosis was $100 \%$ (sensitivity) and 87\% (specificity), 83\% (positive predictive value) and $100 \%$ (negative predictive value) respectively with statistically significant $\mathrm{p}$ value $(<0.05)$.

\section{DISCUSSION}

Tuberculosis is a common cause of pleural effusion ${ }^{7}$ especially in Nepal. The incidence of tuberculosis is increasing worldwide. $^{8}$ Although tubercular pleural effusion can resolve spontaneously but up to $65 \%$ untreated tubercular pleural effusion can develop active tuberculosis. ${ }^{9}$ So, rapid and accurate diagnosis and prompt treatment is necessary for tubercular pleural effusion. Whenever a patient of pleural effusion presents, the usual investigation is in the form of gross, microscopic and biochemical parameters including ADA level. Although lymphocytic predominant fluid is usually seen in tubercular pleural effusion but all lymphocytic predominant fluid can't be tubercular, it could be malignant. ${ }^{10}$ Piras et al were one of the earliest workers who studied ADA activity in pleural effusion of different etiology and concluded that the tubercular pleural fluid ADA activity was significantly higher when compared to 
Table 5: Comparison of ADA activity, Lymphocytosis in pleural fluid and combined value showing sensitivity, specificity, Positive predictive value (PPV) and negative predictive value (NPV)

\begin{tabular}{lccccc}
\hline \multicolumn{5}{c}{ Criteria used to diagnose Tuberculosis } \\
\hline ADA level & Pleural fluid Lymphocytosis & Sensitivity $\%$ & Specificity $\%$ & PPV\% & NPV\% \\
$>40 \mathrm{U} / \mathrm{L}$ & - & $92 \%$ & $92 \%$ & $80 \%$ & $97 \%$ \\
$>40 \mathrm{U} / \mathrm{L}$ & $>50 \%$ Lymphocytosis & $100 \%$ & $87 \%$ & $83 \%$ & $100 \%$ \\
- & $>50 \%$ Lymphocytosis & $85 \%$ & $32 \%$ & $31 \%$ & $86 \%$ \\
\hline
\end{tabular}

different non tubercular cases ${ }^{11}$ which is similar to this study.

The immediate cause of the effusion in TB is a delayed hypersensitivity response to mycobacterial antigen in the pleural space. For this reason microbiological analyses are often negative and limited by the lengthy delay in obtaining results. In areas with high TB prevalence, pleural fluid ADA levels greater than $40 \mathrm{U} / 1$ argue strongly for TB; in contrast, low levels of pleural ADA have high negative predictive value in low-prevalence countries. ${ }^{12}$ The presence of ADA in pleural fluid reflects cellular immune response in pleural cavity and in particular, the activation of T lymphocytes. ${ }^{13}$ ADA has gained increasing attention as a diagnostic tool, especially in countries where the prevalence of TB is high. It achieves a high sensitivity (90 to $100 \%$ ) and is inexpensive and easy to measure. ${ }^{14}$

In this present study, tuberculosis accounted for $26 \%$ of all cases. ADA level was raised ( $\geq 40 \mathrm{U} / \mathrm{L})$ in $92 \%$ of tubercular pleural effusion which correlates well with the conclusion made by Castro et al, in which they stated that adenosine Deaminase level $<40 \mathrm{IU} / \mathrm{L}$ virtually excludes tuberculosis in lymphocytic pleural effusions. ${ }^{15}$ Non-tubercular causes of pleural effusion were COPD, miscellaneous causes (which included cholelithiasis, anemia, fever-PUO, laparotomy, UGI bleeding, renal diseases), idiopathic cases, parapneunomic effusion, road traffic accident, malignancy and auto-immune (rheumatoid arthritis).

The sensitivity and specificity of ADA alone was $92 \%$ each in this study which correlates well with other studies ${ }^{7,16}$ whereas the sensitivity improved to $100 \%$ when the value of lymphocytosis was combined with pleural fluid ADA levels. The results correlated well with other researchers. ${ }^{7,15}$ Devkota et al studied 100 cases of pleural effusions in which they found out that mean ADA level was $105.8+$ 67.23 in TB which was much higher than other etiologies. The sensitivity of ADA was $90.8 \%$ with specificity of $82.8 \%$ when the cut off value was $42.9 \%{ }^{16}$ The sensitivity and specificity of ADA alone to diagnose tubercular pleural effusion was $92 \%$ each and when lymphocyte alone was considered sensitivity was $85 \%$ with specificity of $32 \%$ whereas the combined effect of ADA in effusion with pleural fluid lymphocytosis was $100 \%$ (sensitivity) and $87 \%$ (specificity), 83\% (positive predictive value) and 100\% (negative predictive value) respectively with statistically significant $\mathrm{p}$ value $(<0.05)$.
From this data, it can be concluded that the combination of pleural fluid differential count (lymphocytosis $>50 \%$ ) and ADA level $(\geq 40 \mathrm{U} / \mathrm{L})$ provides us with much more positive result than each component alone. Mehta et al studied 171 patients which showed that pleural fluid ADA $>40 \mathrm{U} / 1$ yielded $85.7 \%$ sensitivity, $80.8 \%$ specificity, $75 \%$ positive predictive value and $89.5 \%$ negative predictive value. The median ADA for TB effusion was $51.8 \mathrm{IU} / \mathrm{ml}$. Hence they concluded pleural fluid ADA is cost effective and good screening test for diagnosis of tuberculosis. ${ }^{6}$ Castro et al studied 410 cases of lymphocytic pleural effusion. The negative predictive value of the ADA test was very high (99\%) similar to the present case. They also stated that with the decline in the prevalence of tuberculous pleural effusion in some areas, the positive predictive value of pleural fluid ADA also declines but the negative predictive value remains high. ${ }^{15}$ Besides, lymphocyte count and ADA level in pleural fluid, even other parameters like protein, sugar and red blood cell counts will also help to build up a conclusion towards etiology as stated by Liam et al. This study showed that a higher proportion of patients with tuberculosis had lymphocyte predominant effusion and tuberculous effusion had higher lymphocyte percentage, lower red cell count and higher protein content. However, there was considerable overlap of these characteristics in maliganant and tubercular effusions. ${ }^{17}$

Newer school of thoughts has been provided by a study done by Mohan et al suggesting that the combined use of adenosine Deaminase activity along with lymphocyte neutrophils ratio would provide a more efficient means for diagnosing tuberculosis pleuritis than the use of ADA alone ${ }^{18}$ Measuring the isoenzymes of ADA particularly estimation of activity of both ADA-1 and ADA-2 isoenzymes and 2'-deoxyadenosine/adenosine activity ratio also improvises the diagnostic efficacy according to Desai et $\mathrm{al}^{19}$ and Safianowska et al. ${ }^{20}$

\section{CONCLUSION}

In conclusion, this can be stated that the measurement of ADA level in pleural fluid in combination with the differential count of pleural fluid will give best results to categorize and to rule in the diagnosis of tubercular pleural effusion. The ADA is relatively inexpensive, easy to perform and less time consuming test whereas lymphocytosis in pleural fluid being an easily available test, these tests are 
very helpful in countries with limited resources.

\section{ACKNOWLEDGEMENT}

I would like to thank Dr Bharati Shakya for her valuable help in statistics and all the colleagues and lab members for their help during the study period.

\section{REFERENCES}

1. Tay TR, Tee A. Factors affecting pleural fluid adenosine deaminase level and the implication on the diagnosis of tuberculous pleural effusion: a retrospective cohort study. BMC Infectious Diseases 2013;13:546. Crossref

2. Kashinkunti M, Antin S S, Darshana R, Dhananjaya M. Use of Pleural Fluid Lymphocyte Neutrophil Ratio in Addition to Pleural Fluid Adenosine Deaminase for the Diagnosis of Tuberculous Pleural Effusion. Sch J App Med Sci 2014;2:498-501.

3. Sharma SK, Suresh V, Mohan A, kaur P, Saha P, Kumar A. A prospective study of sensitivity and specificity of Adenosine deaminase estimation in the diagnosis of tuberculosis pleural effusion. Indian J chest Dis Allied Sci. 2001;43:149-55. Crossref

4. Priyadarshini KS, Aliya nussrath, Devaki RN, BK Manjunatha Goud, Deepa K. A study of pleural fluid Adenosine Deaminase activity in tubercular and non-tubercular pleural effusion. Int J Pharm Sci Rev Res. 2013;23:13-6.

5. De Oliveira HG, Rossatto ER, Prolla JC. Pleural fluid adenosine deaminase and lymphocyte proportion: clinical usefulness in the diagnosis of tuberculosis. Cytopathology. 1994;5:27-32. Crossref

6. Mehta AA, Gupta AS, Ahmed S, Rajesh V. Diagnostic utility of adenosine deaminase in exudative pleural effusions. Lung India. 2014;31:142-4. Crossref

7. Light RW. Pleural diseases. 3rd ed. Baltimore, MD: Williams and wilkins; $1995.754 \mathrm{pp}$.

8. Dolin PJ, Raviglione MC, Kochi A. Global tuberculosis incidence and mortality during 1900-2000. Bull world heath organ. 1994;72:21320 .

9. Roper WH, Waring JJ. Primary serofibrinous pleural effusion in military personnel. Am Rev Tuberc. 1955;71:616-34. Crossref
10. Verma SK, Dubey AL, Singh PA, Tewerson SL, Sharma D. Adenosine Deaminase (ADA) Level in Tubercular Pleural Effusion. Lung India. 2008;25:109-10. Crossref

11. Piras MA, Gakis C, G Andreoni. Adenosine deaminase activity in pleural effusion: An aid to differential diagnosis. Br Med J. 1978;2:1751-2. Crossref

12. Porcel JM. Tuberculous pleural effusion. Lung. 2009;187:263-70. Crossref

13. Sahn SA. The pleura (state of the art). Am Rev Respir Dis 1988;138:184-234. Crossref

14. Ogata Y, Aoe K, Hiraki A, Murakami k, Kishino D, Chikamori K. Is Adenosine Deaminase in pleural fluid a useful marker for differentiating tuberculosis from lung cancer or mesothelioma in Japan, a country with intermediate incidence of tuberculosis? Acta Med. Okayama, 2011;65:259-63. Crossref

15. Jiménez Castro D, Díaz Nuevo G, Pérez-Rodríguez E, Light RW. Diagnostic value of adenosine deaminase in nontuberculous lymphocytic pleural effusions. Eur Respir J. 2003;21:220-4. Crossref

16. KC Devkota, Shyam BK, K Sherpa, P Ghimire, MT Sherpa, R Shrestha and S Gautam. Significance of adenosine deaminase in diagnosing tuberculous pleural effusion. Nepal Med Coll J 2012;14:149-52. Crossref

17. Kashinkunti M, Antin S S, Darshana R, Dhananjaya M. Use of Pleural Fluid Lymphocyte Neutrophil Ratio in Addition to Pleural Fluid Adenosine Deaminase for the Diagnosis of Tuberculous Pleural Effusion. Sch. J. App. Med. Sci. 2014;2:498-501.

18. Desai A, Grolleau-Julius A, Yung R. Leukocyte function in the aging immune system. J Leukoc Biol 2010;87:1001-9. Crossref

19. A Safianowska, R Krenke, B Dmowska-Sobstyl, E BogackaZatorska, J Domagala-Kulawik R Chazan. Adenosine deaminase activity in tuberculous and malignant plural effusions. Pneumonol Alergol Pol. 2006:74:5-9. Crossref

20. C K Liam. Differences in Pleural Fluid Characteristics, White Cell Count and Biochemistry of Tuberculous and Malignant Pleural Ehusions. Med J Malaysia 2001;55:21-8. 